\title{
Assessing the Impact of Human Capital's Structure on High Value-Added Economic Sectors in European Countries: Illustration of Mining Industry
}

\author{
Arturas JURGELEVICIUS ${ }^{1 *}$ and Manuela TVARONAVICIENE ${ }^{2}$
}

\author{
Authors' affiliations and addresses: \\ ${ }^{1}$ Mykolas Romeris University, Institute of \\ Business \& Economics, Ateities 20, Vilnius, \\ Lithuania \\ e-mail: a.jurgelevicius@mruni.eu \\ ${ }^{2}$ Vilnius Gediminas Technical University \\ (Vilnius Tech), Department of Business \\ Technology and Entrepreneurship, Sauletekio av. \\ 11, Vilnius, Lithuania. \\ e-mail: manuela.tvaronaviciene@ vilniustech.lt \\ *Correspondence: \\ Arturas Jurgelevicius, Mykolas Romeris \\ University, Institute of Business \& Economics, \\ Ateities 20, Vilnius, Lithuania \\ tel.: +37068494283 \\ e-mail: a.jurgelevicius@mruni.eu
}

How to cite this article:

Jurgelevicius, A. and Tvaronaviciene, M. (2021). Assessing the impact of human capital's structure on high value-added economic sectors in European countries: illustration of mining industry. Acta Montanistica Slovaca, Volume 26 (1), 106-116

DOI:

https://doi.org/10.46544/AMS.v26i1.09

\begin{abstract}
The aim of the research was to assess the impact of a new structure of human capital on high value-added economic sectors in European countries. The conducted theoretical and empirical research has shown that the proposed new concept of human capital has a place to be. Three dimensions of human capital, such as quality, quantity and value, have different impacts on different sectors of European economies. Based on empirical data, the multiple linear regression model was chosen as a method that the best-fit structure of the data collected. The proposed econometric model revealed that the value of human capital is the most important component among three having very close statistical interconnections with qualitative dimensions. It was researched that Scandinavian countries scored the highest level of value dimension of human capital as well as high value-added in the economy. Open, trusted, tolerant, culturally diverse societies create preconditions for a rise for creative culture, which is a source for the formation of technological innovations and adaptation in high value-added economic sectors. Moreover, because of this value-added chain, technological innovations penetrate traditional industries as mining brings the reduction of cost, the increase in productivity and value-added, safety, and shared value in society through environmental issues.
\end{abstract}

\section{Keywords}

Human capital, high value-added, resources, technological innovations, mining sector and industry. 


\section{Introduction}

Human capital is a dynamic and constantly changing phenomena in economic science. Changing economic structure has significant impacts on human capital composition. On the other hand, the human capital's structure creates preconditions for economic development and growth, new measures of production or new sources of added value or threats (Gerasimov \& Sharafuidino, 2019; Prasetyo \& Kistanti, 2020; Laužikas \& Miliūtė, 2020; Bombiak, 2020; Kardas, 2020).

Although the human capital theory is not a new field in economic science debates, the real and objective role of human capital and its role in the XXI century economy has been poorly revealed. Although the influence of human capital on economic growth is widely analysed in scientific literature, scholars often ignore the important fact that the structure of human capital is much more than just traditional factors such as knowledge and skills. In addition to this, very often, only quantitative indicators of human capital are used in the research. Therefore, science is not known to date as to what extent qualitative human capital indicators determine its value. The quality of human capital reflects itself through more rational behaviour of individuals in uncertain life situations, as the market economy is, through new ideas and productive knowledge needed to create added value under the conditions of 4.0. Industrial revolution.

On the other hand, values that are embedded in human capital, individual attitudes and behavioural norms are equal, or perhaps more important, in the process of creating high added value or in social interaction with other individuals. Only with certain values, beliefs and attitudes individuals can engage in more intense social and economic interaction resulting in new productive ideas and knowledge, more creativity, new production methods, social innovations and new technologies in the economy. Tolerance, openness, cultural diversity and trust are such values that allow recognising the worldview of another individual, makes preconditions to create the most favourable socio-psychological environment for individuals to achieve and realise their maximum potential and self-expression by increasing the value of human capital. The aforementioned values are a source of creative culture and creativity that leads to new and sophisticated production and products.

Meanwhile, at the macro level, there is a significant lack of research on the components of human capital in terms of quantitative, qualitative and value dimensions and the interrelationships among those dealing with the modern economy. Although fragmented researches empirically confirm the positive impact of human capital's quantitative, qualitative and value components on the economy, it is not clear what relationships interdependence and causality exist among these dimensions, how to estimate the size of each dimension and what levels of each dimension imply in European countries, how these different dimensions are important in the different stages of the economic development, how to explain relationships, causality and the content of impact.

This paper presents an econometric model of human capital components impact on high value-added economic sectors in European countries. The rest of the paper proceeds as follows: section two is on literature review, and the third section discusses the research methodology in more detail. Results of the analysis are presented in section four, and conclusions are given at the end of the paper.

In order to clarify the role and significance of human capital in the constantly changing structure of the economy, the field of scientific discussion has been expanded by discussing the latest research and its trends in the field of human capital theory. The traditional approach of scholars to human capital is not a sufficient method to perform a thorough analysis in the current objective reality.

The concept of human capital in the research was divided into three components is due to the fact that the existing human capital assessment methodologies do not cover various aspects of human capital phenomena. Human capital is assessed from a classical perspective, including indicators that usually reflect only knowledge or skills and do not include other significant, and perhaps more significant, elements of human capital in the context of the current modern economy. Recent research suggests that including qualitative aspects of human capital in the analysis has a more significant impact on the economy than classical metrics, which are often quantitative in nature.

\section{Theoretical Background}

Recent empirical research suggests that the impact of human capital on economic growth rates is controversial and ambiguous. Although a number of authors (Barro, 1991; Mankiw \& Romer, 1992; Gemmell, 1996; Topel, 1999; Krueger \& Lindahl, 2001; Pritchett, 2008; Hanushek \& Woessman, 2008, Hanushek \& Schwerdt, 2017; Mazzanti et al., 2020) identifies statistically significant and positive relationships between human capital and economic growth, some authors (Caselli \& Esquivel, 1996) identify statistically negative or statistically insignificant (Knowles \& Owen, 1995; Pritchett, 2008; Hanushek \& Kimko, 2000; World Bank, 
2007; Korauš et al. 2018), or even nonlinear (Kalaitzidakis \& Mamuneas, 2001; Prakash \& Garg, 2019). the relationship between classical human capital concept and economic growth.

Quantitative indicators of human capital have been used in many of these studies. It is worth noting that many studies that have used an average learning duration indicator to assess human capital have been based on erroneous assumptions. First, it was thought that each year of learning in different countries provides the same increase in knowledge and skills, regardless of the quality of different education systems.

Second, it is assumed that each year of schooling, for example in the Switzerland education system, results in the same change in human capital productivity as each year of schooling, for example in Uruguay.

Third, the authors noted (Pritchett, 2008; Islam, 2010) another gap in the application of this indicator. Such an assessment assumes that the source of knowledge and skills is an exclusively formal education system, ignoring other sources of knowledge not related to the formal education system. Thus, the influence of individual innate personal characteristics, talent, family and non-formal education systems, and cultural differences is not included in the analysis of most human capital assessments.

According to Pritchett (2008), in order to find new ways of measuring human capital and relating to economic growth rates, it is necessary to expand and distinguish the quantitative and qualitative characteristics of human capital.

The statements by Mincer, Becker, Schultz, and other pioneers of the human capital theory that the duration of learning affects the size and income of human capital appear to be erroneous in the current economic reality. Pritchett (2008) makes it clear that over the last few decades, learning duration and learning scope have increased several times in many parts of the world but economic growth rates have remained fairly stable or even in some cases tended to decline.

The researchers firmly stated that learning has become massive in many developed countries, there has been a convergence of levels of education, learners' growth rates are much higher than economic growth rates. Moreover, in some developing countries an increase in the duration of learning even leads to a negative change in productivity. Hanushek \& Kimko (2000), Hanushek \& Woessmann $(2008,2015)$ were among the first to try to close the gaps, the lack of knowledge and to try to find more reliable human capital's assessment methodologies.

Another critical aspect that is ignored by human capital theory promoters is a number of values, beliefs and attitudes that are embedded in humans themselves. These values, attitudes, beliefs determine the behaviour of humans in society as well as economic life both from the production side as well as consumption side.

Fragmented researches have been carried out assessing different values, beliefs and attitudes of humans. However, most of them are not comparative or not proceed at the macro level.

According to Inglehart \& Borinskaya (2013), tolerance as a value is important in itself. Tolerance creates the preconditions for a person to live the way he or she wants the best at the same time not being condemned by society. Such a feeling gives a person the impression of happiness.

Corneo \& Jeanne (2009) describe tolerance as respect for diversity, and Florida (2003) argues that tolerance, openness, recognition, and inclusion for all ethnic groups, races or people's lifestyles is critical.

Berggren \& Nilsson (2013) define tolerance as respect for those who are different. Tolerance, the totality of an individual's qualities, allows an individual to lead the lifestyle he or she desires without the surrounding criticism or negative emotions.

Landes (1998) argues that a lack of tolerance has a negative impact on economic growth. It should be noted that tolerance, openness, and diversity play a more important role in a socio-cultural environment where diverse minorities are found (Corneo \& Jeanne, 2009). The existing majority can impose its values and attitudes on minorities and that would lead to social isolation.

Human values such as tolerance, trust, openness and diversity are linked to the potential of the economy. After studying economic development from a retrospective perspective, Mokyr (1990) concludes that innovation requires tolerance and diversity.

In modern economic science literature, R. Florida has left one of its original and most striking traces. R. Florida (2002; Florida \& Tinagli, 2004; Florida \& Mellander, 2008) argues in his and co-authors work that tolerance, openness, and diversity influence technology and economic development. R. Florida (2003) argues that spaces characterised by tolerance and openness have fewer barriers attracting talent and creative-minded people.

R. Florida (2002) finds a positive relationship between the creative class and the high-tech the industry in various United States. In another study, the author (2008) finds a positive effect of tolerance on income levels in the USA. 
Boshma \& Fritsch (2007) found that there is an interaction between declining unemployment and the creation of new businesses and tolerance, measured as part of the creative class and the number of foreign-born infants in the country. According to Ottaviano \& Peri (2006) American citizens born in more culturally diverse urban areas are more productive.

In exploring the ethnic diversity of top executives at the London city level, Nathan \& Lee (2013) determine the nonlinear relationship with the company's turnover. The author explains the higher turnover by the fact that greater ethnic diversity encourages innovation and lower barriers to entering new markets. Meanwhile, Galinsky $\&$ Todd (2015) argue that, on the one hand, more homogeneous groups are characterised by narrower thinking. On the other hand, groups with ethnic diversity are characterised by innovative and high-quality solutions in a competitive context.

Weckroth (2016) finds out that value-based human capital and economic output have strong statistical relationships especially in Scandinavian and Western European regions. Scholars admitted that human-based values and economic performance are complex phenomena. Scholars identified the economic outputs as GDP saying that more accurate measures can be used to evaluate value-based human capital's impact on the economy. (Korshenkov \& Ignatyev, 2020).

Rapid advances in technological innovation, including throught automation, digitisation and electrification, are having a fundamental impact on many traditional economic sectors such as mining. A few technologies reshaping the sector include autonomous vehicles, automation drilling and tunnel systems, drones, 3D printing, remote opertions centre, advanced analytics and simulations modelling, artificial intelliggence, smart sensors and others (Intergovernmental forum on Mining, Minerals, Metals and Sustainable Development., 2018; WEF, 2017). All these emerging technologies invented mainly in the software development industry will have spillover effects into the mining industry.

The World Economic Forum (2017) estimates autonomous machines will be commonplace by 2025, and having these machines operating 24 hours a day, every day, at high levels of productivity and with lower personnel costs could add USD 56 billion in value to the mining industry. However, there are concerns that the fundamental relationships underpinning the social license of mining companies to operate become increasingly strained due to the downward labour pressures associated with automation. Governments will need to ensure automation and artificial intelligence (AI) technologies do not undermine shared value efforts, such as employment and investment in local communities or dividing the sector into low-paying, low-skilled jobs and high-paying jobs for individuals who can take advantage of the shift to new technologies (Intergovernmental forum on Mining, Minerals, Metals and Sustainable Development., 2018).

Introducing emerging technlogies into the mining industry can benefit all major stakeholders - society and shareholders. The mentioned technologies reduce the operating, reduce the risks of workers that face real physical danger in remote areas, creates new jobs, reduce carbond dioxid emissions. The drivers of this shift towards integrating innovation in mining are many and well known. Labour costs are high for many mining companies, with large wage premiums in the sector due to skills shortages and an ageing workforce. Automated technologies allow companies to remove staff from dangerous working conditions. Efficiency and productivity gains can be substantial, particularly for those companies operating in remote areas with high fuel costs. The costs of such technology are falling, sometimes rapidly, giving companies further opportunities to reduce and manage their operating costs in the face of volatile commodity markets. And as these technologies are increasingly proven to be commercially viable, the risks associated with their adoption decrease and companies themselves face pressures to compete with technology leaders (Intergovernmental forum on Mining, Minerals, Metals and Sustainable Development, 2018; Sanchez \& Hartlieb, 2020; Bartos, 2007; Pietrobelli \& Marin, 2018).

For example, it is estimated that utilising smart sensors could create USD 34 billion in value for the mining industry by facilitating predictive maintenance, improving equipment utilisation, reducing downtimes and equipment failures, and lowering the frequency of health and safety incidents. Through improved health and safety, digitisation could also save an estimated 1,000 lives and avoid 44,000 injuries.

However, despite the fact that technological innovations rapidly penetrate into traditional sectors like mining, the main assets of such industries remain human capital (Zaplatina \& Bikmetov, 2018). The human workforce has to be properly trainned with digital skills, remote vehicles control and other technological innovations.

That's why in this research economic output measuring indicators were selected in that way that reflect all sectors where high added value can be created. Like patents, venture capital investments, technology adoption and some others, it was assumed that human capital's value dimension is more important in productive knowledge generation, transfer and adoption in the market.

To conclude, in this research paper, the economic output was identified by knowledge-intensive sectors that accumulate more productive knowledge, including traditional economic sectors as mining, metals or any other. It 
is assumed that such human values as trust, openness, cultural diversity and tolerance are essential for social interaction and collaboration in society to produce high added-value goods and services in emerging technological sectors that have strong spillover effects in traditional ones.

\section{Material and Methods}

In connection with the stated objective of the research, several methods have been chosen. In order to estimate the level of components of human capital, a composite indicator was chosen (OECD, 2008). To identify the relationships among human capital components and knowledge-intensive sectors, a linear multiple regression analysis was conducted.

The process of estimation of the composite indicator can be summarised and presented as follows: $1^{\text {st }}$ stage theoretical background analysis; $2^{\text {nd }}$ stage formation of a preliminary system of indicators; $3^{\text {rd }}$ stage collection of preliminary data; $4^{\text {th }}$ stage data normalisation; $5^{\text {th }}$ stage analysis of data's suitability for research for various criteria; $6^{\text {th }}$ stage determination of weights for indicators; $7^{\text {th }}$ stage estimation for composite indicators; $8^{\text {th }}$ stage sensitivity analysis and interpretation of the results.

Table 1. The indicators representing human capital's structure

\begin{tabular}{|c|c|c|c|c|}
\hline Dimension & $\begin{array}{l}\text { Sub } \\
\text { dimensions }\end{array}$ & Indicator & Type & No \\
\hline \multirow{6}{*}{$\begin{array}{l}\text { Quality } \\
\text { dimension } \\
\text { of HC }\end{array}$} & \multirow{3}{*}{ Cognitive skills } & Quality of math and science education & $\max$ & $X 1$ \\
\hline & & Quality of the educational system & $\max$ & $X 2$ \\
\hline & & Quality of primary education & $\max$ & X3 \\
\hline & \multirow{3}{*}{ Health } & Life expectancy at birth & $\max$ & $X 4$ \\
\hline & & Life expectancy at 65 age & $\max$ & $X 5$ \\
\hline & & Health expenditure by GDP & $\max$ & X6 \\
\hline \multirow{2}{*}{$\begin{array}{l}\text { Quantity } \\
\text { dimension } \\
\text { of } H C\end{array}$} & \multirow{2}{*}{$\begin{array}{l}\text { Education } \\
\text { attainment }\end{array}$} & Mean years of schooling & $\max$ & $Z 1$ \\
\hline & & Labor force with tertiary education & $\max$ & $Z 2$ \\
\hline \multirow{6}{*}{$\begin{array}{l}\text { Values } \\
\text { orientation } \\
\text { of } \mathrm{HC}\end{array}$} & \multirow{2}{*}{ Tolerance } & $\begin{array}{l}\text { People that would not like to have Muslims as } \\
\text { neighbors }\end{array}$ & $\min$ & V1 \\
\hline & & $\begin{array}{l}\text { People that would not like to have homosexuals as } \\
\text { neighbors }\end{array}$ & $\min$ & $V 2$ \\
\hline & \multirow[t]{2}{*}{ Openness } & $\begin{array}{l}\text { People that would not like to have people of a } \\
\text { different race as neighbors }\end{array}$ & $\min$ & V3 \\
\hline & & People that would say they are not a religious person & $\max$ & V4 \\
\hline & Trust & $\begin{array}{l}\text { People that say, generally speaking, most people can } \\
\text { be trusted }\end{array}$ & $\max$ & V5 \\
\hline & Diversity & $\begin{array}{l}\text { People that would not like to have immigrants / } \\
\text { foreign workers as neighbors }\end{array}$ & $\min$ & V6 \\
\hline
\end{tabular}

Each selected indicator introduced in the forward analysis (see Table 1) was analysed based on previous scientific researches and statistical analysis such as descriptive statistics, factor analysis or correlation metrics. Only statistically significant and important indicators were left in the analysis.

Data of the research was collected and extracted from international databases: World's Development Indicators (World Bank) for X6, Z2, UNESCO for X4, EUROSTAT for X5, European Value Survey for V1, V2, V3, V4, V5, V6, World Economic Forum for X1, X2, X3, United Nations for Z1.

The research type is quantitative research. The research period was chosen for V1, V2, V3, V4, V5, V6 1990, 1990, 2008. Value indicators collected every 10 years because they have little change over a short period of time. To reduce potential outliers, it was decided to choose the last 3 available periods of data. Since these data are collected every ten years, the average was estimated. For the rest indicators, the period was chosen for 2008-2010. Based on scientific literature, it is important to mention that human capital indicators have a different impact on the economy over time. A period of 7-10 years was chosen in the research.

Estimating independent variable indicators were chosen, presented in Table 2. High value-added indicators were chosen period of 2016-2018. It was determined by the fact that human capital indicators do not have an immediate effect on the economy. Based on previous research, it was chosen on average 10 years to assess the effect of the human capital dimensions on high value-added economy sectors. 
Table 2. High value-added economy sectors representing indicators (World Economic Forum)

\begin{tabular}{cc}
\hline Risk capital accessibility & E1 \\
\hline FDI and technology transfer & E2 \\
\hline Accessibility of new technologies & E3 \\
\hline New technology adoption & E4 \\
\hline Sophistication of production & E6 \\
\hline Enterprises expenditure on R\&D & E7 \\
\hline University and industry cooperation & E8 \\
\hline Patents & E9
\end{tabular}

To sum up, the sample size of the research was chosen by 37 European countries as they are the most homogenous countries compared to the rest of the world. At the same time, a bigger sample size produces more valid results. In order to estimate the relationship between components of human capital and economy, the linear multiple regression model as a method was chosen. Estimating human capital components, the composite indicator was chosen as a method applicable in estimating extremely heterogeneous phenomena. Estimating dependent variable, principal component analysis was conducted. All assumptions and hypotheses applied to a linear multiple regression model were tested. The index value of the dependent and independent variable has a scale from 0.00 to 1 .

\section{Results}

After conducting principal component analysis for the dependent variable, the key determinants having a higher impact was selected and presented in equation 1 . The equation shows how to estimate the high valueadded economy index in European countries. The indicators determining high value-added economy were selected for final estimations: accessibility of new technologies, new technology adoption, the sophistication of production, university and industry cooperation, innovation potential.

$$
\mathrm{Y}(\mathrm{HVAE})=0,355 *(\mathrm{KE} 3)+0,359 *(\mathrm{KE} 4)+0,358 *(\mathrm{KE} 5)+0,357 *(\mathrm{KE} 6)+0,352 *(\mathrm{KE} 9)
$$

where:

Y - High value-added economy index

KE3 - Accessibility of new technologies

KE4 - New technology adoption

KE5 - Sophistication of production

KE7 - University and industry cooperation

KE9 - Innovation potential

Finally, after creating 8 different econometrical models and analysing all assumptions applicable to the econometrical model, the most accurate model was chosen and estimated using GRETL open-source econometrical software. 
Table 3. Analysis of created econometric models

\begin{tabular}{|c|c|c|c|c|c|c|}
\hline No & Heteroscedasticity & Error distribution & $\begin{array}{c}\text { Multicollin } \\
\text { earity }\end{array}$ & Outliers & $\begin{array}{l}\text { Adjusted R- } \\
\text { squared }\end{array}$ & p-value \\
\hline \multicolumn{7}{|c|}{ I approach } \\
\hline B1 & - & + & + & 5 & 0,753383 & + \\
\hline B2 & + & - & + & 3 & 0,591810 & $+/-$ \\
\hline B3 & - & + & + & 4 & 0,763533 & $+/-$ \\
\hline B4 & - & - & + & 4 & 0,631422 & $+/-$ \\
\hline \multicolumn{7}{|c|}{ II approach } \\
\hline $\mathrm{S} 1$ & + & + & + & 3 & 0,733497 & + \\
\hline $\mathrm{S} 2$ & + & - & + & 3 & 0,601628 & $+/-$ \\
\hline S3 & + & + & + & 3 & 0,754112 & $+/-$ \\
\hline $\mathrm{S} 4$ & - & - & + & 3 & 0,632580 & $+/-$ \\
\hline \multicolumn{7}{|c|}{ I approach } \\
\hline B1 & \multicolumn{6}{|c|}{$\mathrm{Y}=-0,304751+0,506779 *$ qual_B $+0,363479 *$ quant_B $+0,714989 *$ value_B } \\
\hline B2 & \multicolumn{6}{|c|}{ L_Y $=-2,28483+0,644885 *$ qual_B $+0,676888 *$ quant_B $+1,60462 *$ value_B } \\
\hline B3 & \multicolumn{6}{|c|}{$\mathrm{Y}=1,10462+0,369613 * 1$ -qual_B $+0,0706524 * 1$ _quant_B $+0,374499 * 1$-value_B } \\
\hline B4 & \multicolumn{6}{|c|}{ L_Y $=0,352125+0,466731 * 1$ qual_B $+0,215419 * 1$ _quant_B $+0,877876 * 1$ _value _B } \\
\hline \multicolumn{7}{|c|}{ II approach } \\
\hline S1 & \multicolumn{6}{|c|}{$\mathrm{Y}=-0,309141+0,536342 *$ qual_S $+0,344519 *$ quant_S $+0,729135 *$ value_S } \\
\hline $\mathrm{S} 2$ & \multicolumn{6}{|c|}{ L_Y $=-2,44447+0,490770 *$ qual_ $\mathrm{S}+0,619449 *$ quant $\mathrm{S}+1,98781 *$ value_S } \\
\hline S3 & \multicolumn{6}{|c|}{$\mathrm{Y}=1,10951+0,290027 * 1$-qualt _S $+0,0425509 * 1 \_$quant_S $+0,506961+1 \_$value_S } \\
\hline S4 & \multicolumn{6}{|c|}{$\mathrm{L} \_\mathrm{Y}=0,362025+0,297515 * 1 \_$qualt $\_\mathrm{S}+0,174738 * 1 \_$quant $\_\mathrm{S}+1,27020 * 1$ 1_value_S } \\
\hline
\end{tabular}

$$
\mathrm{KE}=-0,30+0,34 * \mathrm{Quant} \_\mathrm{S}+0,53 * \text { Qual_S }+0,72 * \text { Val_S, }
$$

where:

KE - high value-added economy,

Qual_S - qualitative dimension of human capital,

Quant_S - quantitative dimension of human capital,

Val_S - value dimension of human capital.

Interpretation of the model is as follows:

- if the value of the qualitative variable changes by 0.01 point, the value of the high value-added economy as a dependent variable will change by 0.0053 point if the other variables remain unchanged.

- if the value of the quantitative variable changes by 0.01 point, the value of the high value-added economy as a dependent variable will change by 0.00344 point if the other variables remain unchanged.

- if the value of the value variable changes by 0.01 point, the value of the high value-added economy as a dependent variable will change by 0.00729 points if the other variables remain unchanged.

After calculating and evaluating the most appropriate linear multiple regression model, the constructed linear multiple regression equation showed that all components included in the analytical expression are statistically significant factors causing changes in the higher value-added economy at different magnitudes of impact. Such a finding allows confirming the first hypothesis of the study that all proposed components have a different impact on high value-added sectors. According to the results of the research, the importance of human capital components for the high value-added economy can be distinguished in the following order: a) value component (coefficient - 0.729), qualitative component (coefficient - 0.536), quantitative component (coefficient - 0.344). This distribution of the influence of human capital components on the high value-added economy of European countries allows accepting the second hypothesis raised in the research that the value component is the most significant component of human capital that has the greatest impact on the development of the high valueadded economy.

The conducted study revealed that the highest levels of the human capital value and quality components dominate in Scandinavia and Western Europe, and the lowest in Southern and Eastern Europe and the Balkans. At the same time, it is important to declare that the high value-added proportions in the structure of the economy were identified exactly in Scandinavian countries followed by Western European countries.

Several insights can be made by revealing the content of the influence of the components of human capital. First of all, it is clear that the development of a high value-added economy requires an open, tolerant, culturally diverse and trusting society. In such a society, preconditions arise for individuals to actively enter into social interaction, exchange knowledge and generate new ideas. On the other hand, in such an environment, talents are 
able to reveal and maximise their skills, the entire potential of human capital. Such an environment creates the preconditions for the emergence of innovative production methods, products and startups. The qualitative component of human capital, represented through cognitive skills, also contributes to the development of the high value-added economy through the ability to solve uncertain problems, which is especially relevant in the constantly dynamically changing market economy environment.

Meanwhile, the quantitative component of human capital has a relatively small impact on the high valueadded economy. This can be explained by the fact that the accumulation of knowledge is not in itself the only and necessary condition for turning this knowledge into useful products that customers willing to buy. The study found that knowledge accumulation has a greater impact in countries dominated by lower levels of the high value-added sectors. In such economies, mechanical, automated and routine work dominates in terms of valueadded and number of employees. There is a strong tendency for the value component of human capital to be lower in those economies where the value-added generated by the agriculture sector is relatively higher. This can be explained by the limited social interaction in the agriculture sector, where knowledge transfer is very limited.

In explaining the impact of human capital components on the high value-added economy, it is important to pay attention to the role of creative culture. The creative culture is formed in the interaction of various values that allow individuals to maximise their human capital. In such a positive social-psychological environment, individuals have no fear of expressing their opinions, making suggestions, generating ideas, making failures or ways to solve problems. Negative character or cultural traits do not limit or overshadow the positive and beneficial qualities of individuals.

According to the research, the most successful organisations, cities or countries are ethnically, culturally, religiously diverse. Differences in the worldview of each culture complement productive groups in the production process. Applying the best-accumulated knowledge and skills of different nations in the production process produces advanced and complex products that are a consequence of creative culture. Creative culture enables the talents from different cultures to work together despite existing differences in beliefs, attitudes or values. Especially according to the theory of nations' competitive advantage, representatives of one nation may not have the best knowledge or skills in mechanics, electronics, programming, engineering, architecture, aerodynamics, design or other fields. In order to create successful innovations or launch innovative startups, individuals must accept and acknowledge differences in the behaviour and attitudes of other individuals. Such social-psychological interaction forms creativity and creative culture - the main resources for creating high value-added in the economy. Also, it can be named as social innovation as a new form of people's interaction.

On the other hand, it is not enough to make them successful in the production to create innovations or unique products. Much depends on the structure of the market itself and society, so-called early adopters. Obviously, early adopters, as another side of human capital, have to be more risk takers, open to new technologies, and more willing to try new things. This makes customers buy and consume new products or services and adopt new technologies in the market. Such specific structure of market and society leads to innovation creation and early adoption more likely successful.

Fig. 1 illustrates how technological innovations can be adopted in different stages of traditional industries such as mining (Sanchez \& Hartlieb, 2020). The figure illustrates how various technologies can play a different role in the value creation chain. As shown, novel technologies are producing operational changes across the value chain, and their use is not necessarily exclusive to a specific activity. For example, intelligent operation centres are being implemented for both extraction and processing operations. Likewise, augmented and virtual reality, along with digital twinning, are tools that will enhance the design and construction of mining projects ("Establish" in Fig. 1) and the extraction and processing operations (Sanchez \& Hartlieb, 2020). 


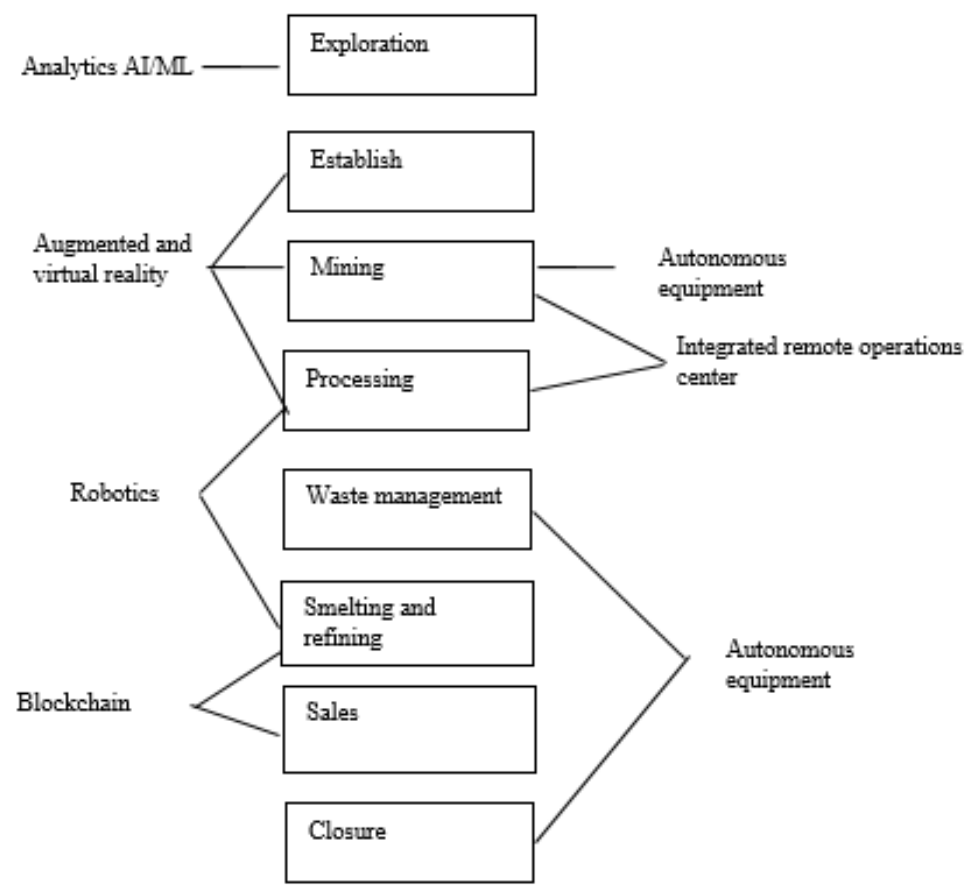

Fig. 1. Technological innovation adoption in different stages of the mining value chain adopted by Sanchez \& Hartlieb (2020)

Moreover, the appearance of creative culture, which leads to creativity, new ideas, technological and social innovations, has a spillover effect for other traditional industries as mining. It was observed that the penetration of technological innovations such as artificial intelligence, autonomous vehicles, smart sensors, remote work and many others has an extremely significant impact on cost reduction, productivity, social safety and shared value in the traditional industries, including mining. Additional to this, the change of industry requires the change of human capital within the industry.

Based on the results of this research, it can be claimed that technological innovations have their own ecosystem that can work as follows: certain human values, beliefs and attitudes accelerate social interaction among individuals, resulting in new ideas and innovations. These products spread in the market, creating disruptive technologies and new industries as well as being introduced to traditional sectors like mining. In both cases, the implication of this kind of value chain results in benefits for societies with more high paid jobs and productivity for businesses.

\section{Conclusions}

This research has revealed the impact of human capital components on a high value-added economy. The formulated econometrical model has shown that human values, attitudes, beliefs are more important factors in high value-added economic activities than quantitative or even qualitative aspects of human capital.

A tolerant, open, culturally diverse and more trusted environment creates preconditions for people to collaborate on different projects, share and transfer knowledge that finally results in high value-added projects or products like innovative startups, innovative goods or services.

Based on the nation's competitive advantage theory, it is possible to notice that workers from every nation can collaborate on different projects creating the most sophisticated products for the customers. In this way, customers utilise all benefits of the consumption and can get the best products available on the market. Moreover, a more open, tolerant, trusted, culturally diverse society as an early adopter of new technologies can buy and consume new products with more motivation that pays the way to innovation adaptation. These preconditions become critically important as in the early stage of innovation, the evidence needed that the demand among costumers exists for the new products, and further investments, usually from venture capital funds, can be made. 
As a result of the creation of technological innovations, it can be pointed out that these technologies have a spillover effect and extremely significant impact on traditional sectors as mining. Due to emerging technologies, traditional sectors are forced to experience a deep transformation in the way that they used to operate. New patterns of work, cost reduction, productivity increase, safety is an area that can benefit many traditional sectors as mining.

Future research also can emphasise the impact of human's values, beliefs, attitudes and relations with such phenomena as entrepreneurship, startup buildings and innovations. On the other hand, it is important to research what factors influence such values like openness, tolerance, diversity etc. Last but not least, research direction can contribute to a wide society by analysing social, economic, technological environment factors that are significant for human capital's value dimension formation.

\section{References}

Barro, R. J. (1991). Economic Growth in a Cross - Section of Countries. Quarterly Journal of Economics, 106, $407-443$.

Berggren, N. \& Nilsson, T. (2013). Does Economic Freedom Foster Tolerance? Kyklos, 66(2), 177-207.

Bombiak, E. (2020). Advances in the implementation of the model of sustainable human resource management: Polish companies' experiences. Entrepreneurship and Sustainability Issues, 7(3), 1667-1687. https://doi.org/10.9770/jesi.2020.7.3(16)

Boschma, R. A. \& Fritsch, M. (2007). Creative class and regional growth: empirical evidence from eight European countries. Jena Economic Research Paper No. 66. Jena: Friedrich Schiller University and Max Planck Institute.

Caselli, F. \& Esquivel, G., et al. (1996). Reopening the convergence debate: a new look at cross-country growth empirics. Journal of Economic Growth, 1(3), 363-90.

Corneo, G. \& Jeanne, O. (2009). A Theory of Tolerance. Journal of Public Economics, 93(5-6), 691-702.

Florida, R. \& Mellander, C. (2008). Inside the black box of regional development -human capital, the creative class and tolerance. Journal of Economic Geography, 8(5), 615-649.

Florida, R. \& Tinagli, I. (2004). Europe in the creative age. Co-published in Europe with Demos.

Florida, R. (2003). Cities and the Creative Class. City and Community, 2(1), March. American Sociological Association.

Galinsky, A. D. \& Todd, A. R. (2015). Maximising the Gains and Minimising the Pains of Diversity: A Policy Perspective. Perspectives on Psychological Science, 10(6), 742-748.

Gemmell, N. (1996). Evaluating the Impacts of Human Capital Stocks and Accumulation on Economic Growth: Some New Evidence. Oxford Bulletin of Economics and Statistics, 58(1), 9-28.

Gerasimov, V., Sharafutdinov, R., Kolmakov, V., Erzinkyan, E., Adamenko, A. \& Vasilyeva, A. (2019). Control in the human capital management system in the strategy of innovative development of a region. Entrepreneurship and Sustainability Issues, 7(2), 1074-1088. http://doi.org/10.9770/jesi.2019.7.2(20)

Hanushek, E. A. \& Schwerdt, G. (2017). Coping with change: International differences in the returns to skills. Economics Letters, 153, 15-19.

Hanushek, E. A. \& Woessmann, L. (2008). The Role of Cognitive Skills in Economic Development. Journal of Economic Literature, 46(3), 607-668.

Hanushek, E. A. \& Woessmann, L. (2015). The Knowledge Capital of Nations: Education and the Economics of Growth. Cambridge, MA: MIT Press.

Inglehart, R. F. \& Borinskaya, S. (2013). Genes, security, tolerance and happiness. Working Paper No. BRP 31/SOC. National Research University Higher School of Economics (HSE), Moscow.

Intergovernmental forum on Mining, Minerals, Metals and Sustainable Development. (2018). Innovation in Mining: a report to the 2018 international mines ministery summit. Available at: https://www.igfmining.org/technological-innovation-impacting-mining-sector/. The International Institute for Sustainable Development.

Islam, R. (2010). Quality - adjusted Human Capital and Productivity Growth, Monash University Business and Economics. Department of Economics. Discussion paper 48/10.

Kalaitzidakis, P. \& Mamuneas, T. P. (2001). Measures of Human Capital and Nonlinearities in Economic Growth. Journal of Economic Growth, 6(3), 229-254.

Kardas, J. S. (2020). Job Crafting in individualisation fields of company human resources. Entrepreneurship and Sustainability Issues, 7(3), 1937-1950. https://doi.org/10.9770/jesi.2020.7.3(33)

Knowles, S. \& Owen, P. D. (1995). Health Capital and Cross-Country Variation in income per capita in the Mankiw-Romer-Weil Model. Economics Letters. 48, 99-106.

Korauš, A., Mazák, M., Dobrovič, J. (2018). Quantitative analysis of the competitiveness of Benelux countries, Entrepreneurship and Sustainability Issues, 5(4), 1069-1083. http://doi.org/10.9770/jesi.2018.5.4(26) 
Korshenkov, E. \& Ignatyev, S. (2020). Empirical interpretation and measurement of the productivity and efficiency of regions: The case of Latvia. Insights into Regional Development, 2(2), 549-561. https://doi.org/10.9770/IRD.2020.2.2(4)

Krueger, A. B. \& Lindahl, L. (2001). Education for Growth: Why and for Whom? Journal of Economic Literature, 39(4), 1101-1136.

Landes, D. S. (1998). The Wealth and Poverty of Nations: Why Some Are So Rich and Some So Poor. New York, London.

Laužikas, M. \& Miliūtè, A. (2020). Human resource management effects on sustainability of high-tech companies: what Lithuania and South Korea can learn from each other? Insights into Regional Development, 2(2), 562-579. https://doi.org/10.9770/IRD.2020.2.2(5)

Mankiw, N. G. \& Romer, D. (1992). A Contribution to the Empirics of Economic Growth. The Quarterly Journal of Economics, 107, 407-437.

Mazzanti, M., Mazzarano, M., Pronti, A., Quatrosi, M. (2020). Fiscal policies, public investments and wellbeing: mapping the evolution of the EU. Insights into Regional Development, 2(4), 725-749. http://doi.org/10.9770/IRD.2020.2.4(1)

Mokyr, J. (1990). The lever of riches: technological creativity and economic progress. Oxford: Oxford University Press.

Nathan, M. \& Lee, N. (2013). Cultural Diversity, Innovation, and Entrepreneurship: Firm-level Evidence from London. Economic Geography, 89, (4), 367-394.

OECD (2008). Handbook on Constructing Composite Indicators: Methodology and User Guide

Ottaviano, G. I. P. \& Peri, G. (2006). The economic value of cultural diversity: evidence from U.S. cities. Journal of Economic Geography, 6(1), 9-44.

Pietrobelli, C., Marin, A. \& Olivari, J. (2018). Innovation in mining value chains: new evidence from Latin America. Resources Policy, 58, 1-10.

Prakash, R. \& Garg, P. (2019). Comparative assessment of HDI with Composite Development Index (CDI), Insights into Regional Development, 1(1), 58-76. https://doi.org/10.9770/ird.2019.1.1(5)

Prasetyo, P. E. \& Kistanti, N. R. (2020). Human capital, institutional economics and entrepreneurship as a driver for quality \& sustainable economic growth. Entrepreneurship and Sustainability Issues. 7(4), 2575-2589. https://doi.org/10.9770/jesi.2020.7.4(1)

Pritchet, L. (2008). Does learning to add up add up? The returns to schooling in aggregate data. Handbook of Education Economics. Kennedy School of Government, Harvard University.

Sanchez, F. \& Hartlieb, P. (2020). Innovation in the mining industry: technological trends and a case study of the challenges of disruptive innovation. Mining, Metallurgy \& Exploration, 37, 1385-1399. https://doi.org/10.1007/s42461-020-00262-1

Topel, R. (1999). Labor Markets and Economic Growth, in: Orley Ashenfelter and David Card, eds. Handbook of Labor Economics. Amsterdam: Elsevier Science B.V., 2943-2984.

World Bank (2007). Education Quality and Economic Growth. The World Bank, Washington, DC.

World Economic Forum (2017). Digital Transformation Initiative: Mining and Metals, Industry.

Zaplatina, O. \& Bikmetov, R. (2018). Human Capital and its demand in the mining industry. Web of Conferences 41, 04013, IIIrd International Innovative Mining Symposium. 